NASA Technical Memorandum 106354

ICOMP-93-32

AIAA-93-1917

\title{
Numerical Study of Shock-Induced Combustion in Methane-Air Mixtures
}

Shaye Yungster

Institute for Computational Mechanics in Propulsion

Lewis Research Center

Cleveland, Ohio

and

Martin J. Rabinowitz

National Aeronautics and Space Administration

Lewis Research Center

Cleveland, Ohio

Prepared for the

29th Joint Propulsion Conference and Exhibit cosponsored by the AIAA, SAE, ASME, and ASEE

Monterey, California, June 28-30, 1993

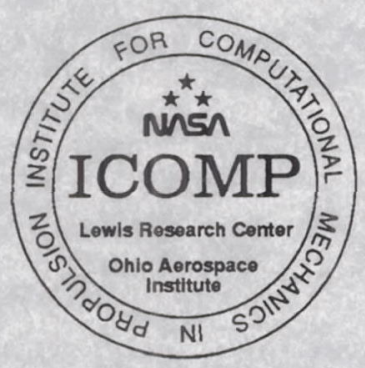




\title{
Numerical Study of Shock-Induced Combustion in Methane-Air Mixtures
}

\author{
Shaye Yungster \\ Institute for Computational Mechanics in Propulsion \\ NASA Lewis Research Center, Cleveland, OH 44135 \\ and \\ Martin J. Rabinowitz \\ NASA Lewis Research Center, Cleveland, OH 44135
}

\begin{abstract}
The shock-induced combustion of methane-air mixtures in hypersonic flows is investigated using a new reaction mechanism consisting of 19 reacting species and 52 elementary reactions. This reduced model is derived from a full kinetic mechanism via the Detailed Reduction technique. Zero-dimensional computations of several shock-tube experiments are presented first. The reaction mechanism is then combined with a fully implicit NavierStokes CFD code to conduct numerical simulations of two-dimensional and axisymmetric shock-induced combustion experiments of stoichiometric methane-air mixtures at a Mach number of $M=6.61$. Applications to the ram accelerator concept are also presented.
\end{abstract}

\section{Introduction}

One of the main obstacles in the computation of highspeed flows with hydrocarbon combustion has been the lack of reliable reaction mechanisms that are reasonably simple and yet still reproduce experimental observations over a wide range of conditions. Detailed kinetic mechanisms have been developed for the simplest fuel molecules. Oxidation models for methane, for example, typically consist of 100-250 elementary reactions, and more significantly, they include from 28 to 50 or more species ${ }^{1-5}$. Since the computational cost associated with a given reaction mechanism depends primarily on the number of species included, the use of these models would be prohibitively expensive when combined with existing two-or three-dimensional CFD codes.

As a result, previous computations of high-speed methane-air flows, aimed at studying detonation waves

Copyright (C) 1993 by the American Institute of Aeronautics and Astronautics, Inc. No copyright is asserted in the United States under Title 17, U.S. Code. The U.S. Government has a royaltyfree license to exercise all rights under the copyright claimed herein for Governmental purposes. All other rights are reserved by the copyright owner. and the ram accelerator concept ${ }^{6}$, have used either simplified quasi-global models ${ }^{7-8}$, or mechanisms composed of elementary reactions whose rate parameters are collected from literature recommendations ${ }^{8}$. Although quasi-global models have the potential to reproduce accurately some flame properties such as flammability limits, combustion temperature and burned gas composition, they generally cannot describe accurately the chemical structure of the flame itself. In shock-induced combustion problems this will translate in an incorrect prediction of the induction zone. In addition, the parameter ranges over which these simplified mechanisms can accurately be applied are rather narrow. A second disadvantage of quasi-global models, such as those developed by Westbrook and Dryer ${ }^{9}$, is their sensitivity to the numerical models used. These models, which combine a single reaction of fuel and oxidizer with a detailed mechanism for a $\mathrm{CO}-\mathrm{H}_{2}-\mathrm{O}_{2}$ system, were developed mainly based on flame speed data. As a result, they depend not only on the rate parameters, but also on thermodynamic and transport properties which may be treated somewhat differently in other codes. Therefore, for use in other codes, it is generally necessary to calibrate the pre-exponential factor in each individual reaction.

On the other hand, mechanisms that are simply a collection of elementary reactions suffer from the following principle:

"A mechanism composed of reactions with best available rate parameters individually is incapable of quantitative predictions when taken as a whole ${ }^{1 "}$.

For these mechanisms, in which the individual reactions may have been validated under conditions of chemical isolation, when combined together they usually do not reproduce experimental observations accurately.

There is therefore a need for a reasonably simple and reliable kinetic mechanism for methane-air combustion. In the present paper we introduce one such model which consists of 19 reacting species and 52 elementary reactions. 
Although this model is still quite complex and requires significant computational power, it has the advantage of giving accurate predictions over a wide range of flow conditions. Its use in practical hypervelocity applications is demonstrated in this paper. The combustion model is combined with a fully implicit CFD code to numerically simulate expansion-tube experiments conducted at the French-German ISL Institute ${ }^{10}$ aimed at studying ram accelerator related combustion phenomena. Results are presented for superdetonative flows of methane-air mixtures around various bodies, and are compared with experimental data and with the computations performed by Soetrisno, Imlay and Roberts ${ }^{8}$. Applications to an axisymmetric ram accelerator projectile are also presented.

\section{Numerical Formulation}

\section{Governing Equations}

The computations are conducted using the NavierStokes equations for two-dimensional or axisymmetric flow, in which the global continuity equation is replaced by all the species continuity equations. They can be expressed in the following conservation form for a gas containing $n$ species and in general curvilinear coordinates $(\xi, \eta)$

$$
\frac{\partial \mathbf{Q}}{\partial t}+\frac{\partial\left(\mathbf{F}-\mathbf{F}_{v}\right)}{\partial \xi}+\frac{\partial\left(\mathbf{G}-\mathbf{G}_{v}\right)}{\partial \eta}+j\left(\mathbf{H}-\mathbf{H}_{v}\right)=\mathbf{W}
$$

where

$$
\mathbf{Q}=J^{-1}\left[\begin{array}{c}
\rho_{1} \\
\rho_{2} \\
\vdots \\
\rho_{n} \\
\rho u \\
\rho v \\
e
\end{array}\right]
$$

The equations describe two-dimensional flow if $j=0$ and axisymmetric flow if $j=1$. The variables are the density of the $i$ th species $\rho_{i}$, with $\rho=\sum_{i=1}^{n} \rho_{i}$, the velocity components $u$ and $v$, and the total energy per unit volume $e . \mathbf{F}$ and $\mathbf{G}$ are the inviscid flux vectors in the $\xi$ and $\eta$ directions respectively. Similarly, $\mathbf{F}_{v}$ and $\mathbf{G}_{v}$ are the viscous fluxes. The terms $\mathbf{H}$ and $\mathbf{H}_{v}$ are the axisymmetric source terms, and $\mathbf{W}$ is the chemical source term. A detailed description of all the terms appearing in Eq. (1) can be found in Yungster ${ }^{11}$.

\section{Reaction Model}

The methane oxidation mechanism used in this study was developed via the technique of Detailed Reduction ${ }^{12}$ starting from the full mechanism of Frenklach, Wang and
Rabinowitz ${ }^{1}$. Detailed Reduction is a systematic method of reducing large reaction networks while maintaining the accurate prediction of selected combustion characteristics. Usually a kinetic mechanism is developed to predict a range of combustion characteristics (ignition, species profiles, flame velocities, pollutant emission, etc.) many of which are not important for a particular application. For detonation calculations the fate of species that do not contribute significantly to heat release or ignition is unimportant. To test the contribution of various species and reactions two criteria were developed:

$$
\left|K_{j}\right|<\epsilon_{K}\left|K_{r e f}\right|
$$

and

$$
\left|K_{j} \Delta H_{j}\right|<\epsilon_{Q} \dot{Q}_{\max }
$$

where, $K_{j}$ is the rate of reaction $j, K_{\text {ref }}$ is the rate of a reference reaction (usually the rate limiting reaction, in this case the reaction of $\left.H+\mathrm{O}_{2} \rightleftharpoons \mathrm{OH}+\mathrm{O}\right), \Delta H_{j}$ is the enthalpy of reaction $j, \dot{Q}_{\max }$ is the maximum heat release per unit time of any reaction, and $\epsilon_{K}$ and $\epsilon_{Q}$ are parameters much smaller than unity. The first inequality tests the contribution of each reaction to chain branching (and hence ignition delay) and the second to heat release. Reactions whose rates, both forward and reverse, satisfy equations 3 and 4 are removed from the mechanism.

A series of zero dimensional calculations were performed with values of $\epsilon_{K}$ and $\epsilon_{Q}$ around 0.1 for 11 shock-tube test cases of premixed methane oxidation. It was found that the complete 33 species, 149 reaction mechanism ${ }^{1}$ could be reduced to 19 species and 52 reactions while still maintaining good accuracy. The results are shown in Table 1 . The computed flame velocity for a stoichiometric, $1 \mathrm{~atm}$ methane flame is $39.2 \mathrm{~cm} / \mathrm{s}$, in close agreement with both experimental value $(40 \mathrm{~cm} / \mathrm{s})$ and the value obtained with the full mechanism $(39.5 \mathrm{~cm} / \mathrm{s})$. The reactions for the reduced mechanism and their rate coefficients are listed in Table 2 in the appendix.

The procedure for calculating the chemical source term $W$ is as follows:

The chemical equation for a general elementary reaction $j$ in a gas mixture containing $n$ species can be written as

$$
\sum_{s=1}^{n} \nu_{s, j}^{\prime} Y_{s} \rightleftharpoons \sum_{s=1}^{n} \nu_{s, j}^{\prime \prime} Y_{s}
$$

where $\nu_{s, j}^{\prime}$ and $\nu_{s, j}^{\prime \prime}$ are the stoichiometric coefficients of reaction $j$. The rate of change of the concentration of species $i$ in reaction $j$, denoted as $\dot{y}_{i, j}$, is given by

$$
\dot{y}_{i, j}=\left(\nu_{i, j}^{\prime \prime}-\nu_{i, j}^{\prime}\right)\left[K_{f, j} \prod_{s=1}^{n} y_{s}^{\nu_{s, j}^{\prime}}-K_{b, j} \prod_{s=1}^{n} y_{s}^{\nu_{s, j}^{\prime \prime}}\right]
$$


Table 1: Ignition Delay (microseconds)

\begin{tabular}{|c|c|c|c|}
\hline IC $^{\dagger}$ & Experiment & Full $^{*}$ & Reduced $^{*}$ \\
\hline 1 & 268 & $236(-12)$ & $245(-9)$ \\
\hline 2 & 46 & $49(7)$ & $51(11)$ \\
\hline 3 & 18 & $22(22)$ & $23(28)$ \\
\hline 4 & 436 & $497(14)$ & $530(22)$ \\
\hline 5 & 99 & $101(2)$ & $107(8)$ \\
\hline 6 & 99 & $97(-2)$ & $99(0)$ \\
\hline 7 & 1512 & $1361(-10)$ & $1378(-9)$ \\
\hline 8 & 550 & $538(-2)$ & $546(-1)$ \\
\hline 9 & 226 & $249(11)$ & $253(12)$ \\
\hline 10 & 205 & $187(-8)$ & $192(-6)$ \\
\hline 11 & 210 & $241(15)$ & $255(21)$ \\
\hline
\end{tabular}

† See Ref. 1 for details of cases IC1 through IC11.

*Percent deviation in parentheses.

where $y_{i}$ is the concentration of species $Y_{i}\left(y_{i}=\rho_{i} / M_{i}\right)$. The total rate of change of the concentration of the $i$ th species caused by all of the chemical reactions is

$$
\dot{y}_{i}=\sum_{j} \dot{y}_{i, j}
$$

The components $w_{i}$ of the chemical source term $W$ are given by

$$
w_{i}=\dot{y}_{i} M_{i}
$$

The forward rate coefficients of pressure-independent reactions are calculated from

$$
K_{f, j}=A_{j} T^{b_{j}} e^{-\Theta_{j} / T}
$$

Note that the dissociation reactions of $\mathrm{CH}_{4}, \mathrm{C}_{2} \mathrm{H}_{5}$ and $\mathrm{C}_{2} \mathrm{H}_{6}$ (reactions 33,48 and 49 ) are in the fall-off region and require special treatment for pressure-dependent rate coefficients. The pressure dependence of these reactions is treated based on the Troe-Golden formalism ${ }^{\text {I }}$

$$
\begin{gathered}
K_{j}^{0}=A_{j}^{0} T^{b_{j}^{0}} e^{-\Theta_{j}^{0} / T} \\
K_{j}^{\infty}=A_{j}^{\infty} T^{b_{j}^{\infty}} e^{-\Theta_{j}^{\infty} / T} \\
P_{r}=\frac{K_{j}^{0}[M]}{K_{j}^{\infty}}
\end{gathered}
$$

where $K_{j}^{0}$ and $K_{j}^{\infty}$ are the low and high pressure limiting rate coefficients and $[M]$ denotes the concentration of the third body. Note that $M$ has been written within parentheses in Table 2 to indicate that it should not be included in Eq. 6.

$$
\begin{gathered}
F_{c}=a_{j} e^{-b_{j} / T}+\left(1-a_{j}\right) e^{-c_{j} / T} \\
x_{t}=\frac{1}{1+\left(\log P_{r}\right)^{2}}
\end{gathered}
$$

The forward rate coefficients of pressure-dependent reactions are then given by

$$
K_{f, j}=K_{j}^{\infty} \frac{P_{r}}{1+P_{r}} F_{c} x_{t}
$$

The rate coefficients of the reverse reactions were determined via equilibrium constants

$$
K_{b, j}=\frac{K_{f, j}}{K_{C, j}}
$$

where $K_{C, j}$ is the equilibrium constant for the $j$ th reaction, and is given by

$$
K_{C, j}=\frac{\exp \left(-\sum_{s=1}^{n} \nu_{s} \mu_{s}^{0} / R T\right)}{(R T)^{\Delta \nu_{s}}}
$$

where

$$
\Delta \nu_{s}=\sum_{s=1}^{n} \nu_{s} ; \quad \nu_{s}= \begin{cases}-\nu_{s}^{\prime} & \text { for reactants } \\ \nu_{s}^{\prime \prime} & \text { for products }\end{cases}
$$

Here, $R$ is the universal gas constant, and $\mu_{s}^{0}$ is the species standard state Gibbs free energy per mole, which is determined from fourth-order polynomials of temperature. (The other thermodynamic and transport properties are also computed using polynomial functions of temperature $\left.{ }^{11}\right)$.

\section{Numerical Method}

The system of equations (1) is solved using a fully implicit finite difference CFD code ${ }^{11}$. It employs an iterative method that is based on the LU-SSOR implicit factorization scheme ${ }^{13}$, and Yee's second order total variation diminishing (TVD) differencing scheme ${ }^{14}$. In the present study, a symmetric TVD scheme with a minmod type limiter is used. The viscous terms are evaluated using standard central differences. The full Jacobian of the chemical source term is used, leading to a preconditioner matrix of size $n \times n$ that has to be inverted at every grid point. The structure of the LU-SSOR algorithm allows full vectorization of the CFD code, including the matrix inversion process which is done using Crout's algorithm (without pivoting). The scheme is suitable for steadystate calculations. Further details about the algorithm can be found in Yungster ${ }^{11}$. 


\section{Results}

\section{Shock-Induced Combustion}

Numerical simulations of two sets of expansion-tube experiments conducted by Srulijes, Smeets and Seiler ${ }^{10}$ at the French-German ISL Institute are presented. Both cases considered a stoichiometric methane-air mixture at a static pressure, $p_{\infty}=0.51$ bar, static temperature, $T_{\infty}=295^{\circ} \mathrm{K}$, and a superdetonative velocity of $U_{\infty}=$ $2330 \mathrm{~m} / \mathrm{s}$ (Mach number $M=6.61$ ). The ChapmanJouguet detonation speed of the gas mixture under these conditions was computed ${ }^{10}$ to be about $D=1800 \mathrm{~m} / \mathrm{s}$.

The first set of experiments consisted of cylindrical steel rods placed perpendicularly to the flow inside a combustion test chamber. For a fixed flow velocity, the diameter of the rods were progressively reduced up to a lower limit beyond which ignition did not occur any more. Two pressure transducers mounted on the tube wall, one placed upstream and the other downstream of the rod, recorded the pressure history. The results of this experiment indicated a sharp ignition onset between a rod diameter of $3 \mathrm{~mm}$ and $4 \mathrm{~mm}$. For a rod diameter of $7 \mathrm{~mm}$, the pressure trace clearly showed the presence of combustion.

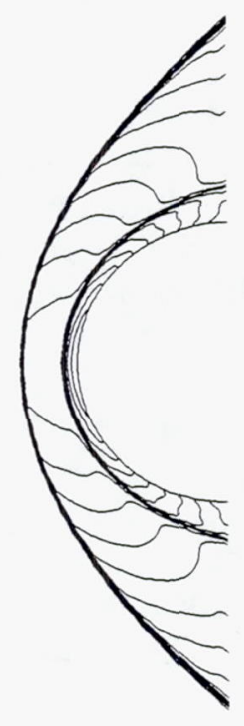

Fig. 1. Temperature contours for a rod diameter of $d=1 \mathrm{~mm}$.

Figures 1-3 show the computational results for three cylindrical rods having diameters of $1 \mathrm{~mm}, 3 \mathrm{~mm}$, and 7 $\mathrm{mm}$ respectively. A $91 \times 91$ grid was used, and the flow was assumed to be inviscid. The results show the advance of the combustion zone, initially constrained to a narrow region near the surface of the smallest rod. towards the bow shock as the diameter of the body is increased. The increase in the amount of combustion as a function of rod size appears to be a continuous process. Therefore, it is probable that the experimental setup of Ref 10 was unable to detect the partial combustion predicted in Figs 1 or 2 because the pressure rise was too small or occurred downstream of the location of the pressure transducer.

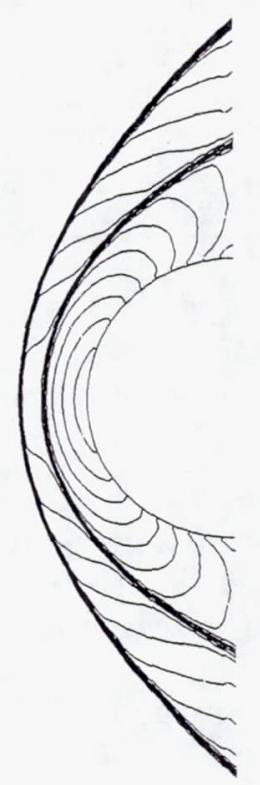

Fig. 2. Temperature contours for a rod diameter of $d=3 \mathrm{~mm}$.

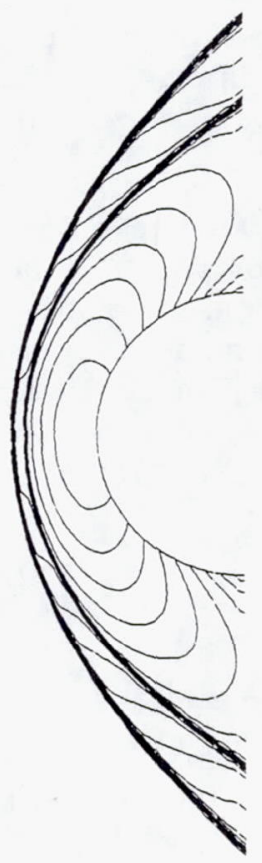

Fig. 3. Temperature contours for a rod diameter of $d=7 \mathrm{~mm}$. 
The same computations were conducted by Soetrisno et. al. ${ }^{8}$ using the quasi-global combustion model of Westbrook and Dryer ${ }^{9}$. Their computations predict essentially a fully coupled shock-deflagration wave for the same three rod diameters studied. These results show the inability of the global models in correctly predicting induction times. The computation of Soetrisno et. al. ${ }^{8}$ for a rod diameter of $0.5 \mathrm{~mm}$ is comparable to the result presented in Fig 3 of the present work for a $7 \mathrm{~mm}$ diameter cylinder. Neglecting the fact that a somewhat coarser grid was used in Ref $8(72 \times 65)$, this indicates that the global model is underpredicting the induction time by approximately an order of magnitude.

Figures 4-5 show the pressure and temperature variation along the stagnation streamline for the three cases. For comparison, the nonreacting solution is also plotted. The shock standoff distance increases with the amount of heat release. The pressure drop behind the shock wave is due to the heat release at subsonic speeds. Figure 6 shows the mole fraction distribution along the stagnation streamline for the $3 \mathrm{~mm}$ cylinder. Note that behind the shock, thermal decomposition of $\mathrm{CH}_{4}$ produces significant amounts of larger hydrocarbons and other radicals within the induction zone. These species then quickly disappear during the heat release process.

These simulations required between 2500 and 3500 iterations (using a maximum CFL number of $\approx 8$ ) and between 7 and 10 hours of CPU time on a CRAY C90. The code achieved 175 MFLOPS during execution, of which virtually all were performed in the vector units. The program, however, appeared to have memory bank conflicts with this number of species. (The same code with an 9-species, 18-reaction $\mathrm{H}_{2}$-air model achieved 250 MFLOPS). A more efficient method for referencing memory is currently being implemented.

The second experiment consisted of a blunt cylinder of $d=7 \mathrm{~mm}$ diameter, having its axis aligned with the flow. The mixture, Mach number, and free-stream conditions were identical to the previous case. Laminar, adiabatic flow alculations were performed on a two-block grid having $75 \times 150$ and $75 \times 91$ points. Temperature contours for this case are shown in Fig. 7. The shock and combustion front are separated by a small induction zone. This induction zone widens downstream due to the weakening of the bow shock caused by the expansion waves emanating from the cylinder shoulder.

The same calculation was also conducted by Soetrisno et. al. ${ }^{8}$ using several combustion models. Their results indicate also a decoupling of the shock and combustion fronts downstream of the shoulder, however, along the stagnation region, the shock and combustion fronts appear to be fully coupled.

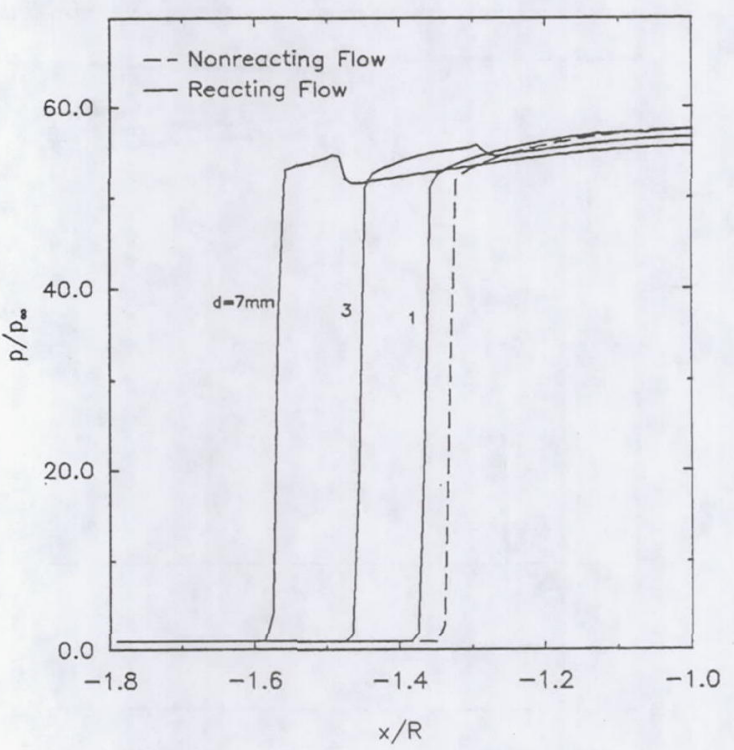

Fig. 4. Pressure distribution along the stagnation streamline.

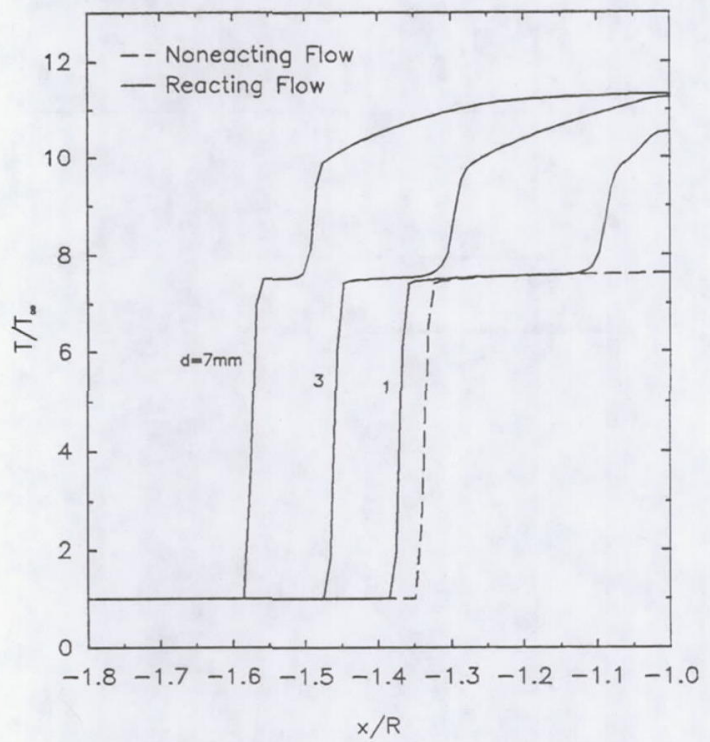

Fig. 5. Temperature distribution along the stagnation streamline. 

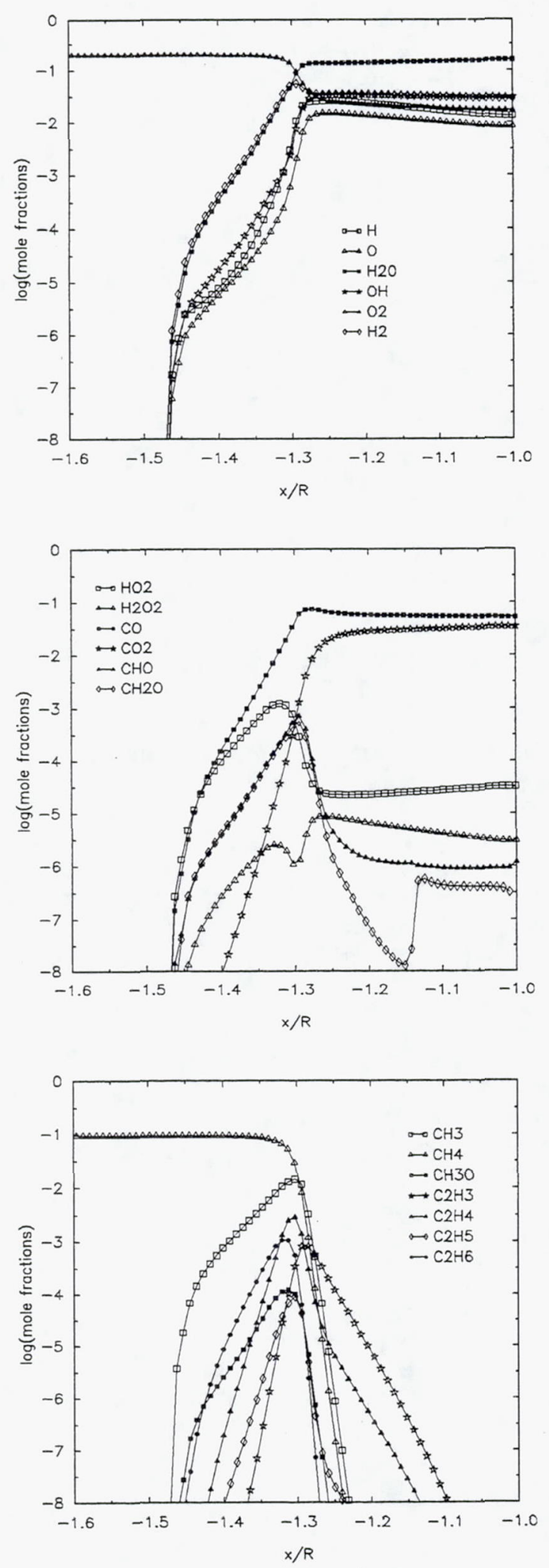

Fig. 6. Concentration profiles along the stagnation streamline; $d=3 \mathrm{~mm}$.

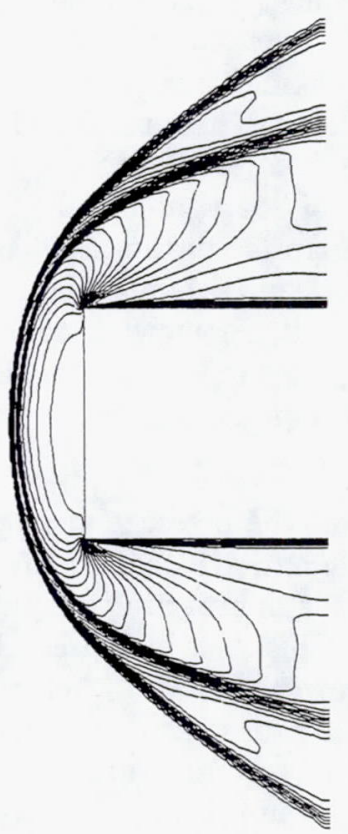

Fig. 7. Temperature contours for a blunt cylinder. $\mathrm{M}=6.61$, stoichiometric $\mathrm{CH}_{4}$-air.

Figure 8 shows the pressure and temperature distribution along the stagnation streamline obtained in the present work, compared with the results of Soetrisno et. al. based on the quasi-global model and a detailed model consisting of 13 species and 19 elementary reactions. All computations give similar pressure distribution with the exception that the von-Neumann spike predicted in the present calculation is not observed in the calculations of Soetrisno et. al. The temperature distribution shows significant differences between the two combustion models used in Ref. 8, with the global model showing a better agreement with the present work. Also, the shock standoff distance was slightly larger for the global model than that obtained in the present work.

A quantitative comparison with the interferometry flow visualization of this case presented in Ref 6 could only be done with respect to the shock stand-off distance. A steady combustion process was reported, with a constant shock stand-off distance $x_{s h}$. The experimental value of $x_{s h} / d \approx 0.29$ is in good agreement with the present results and with the full model of Soetrisno et. al.

\section{Applications to the Ram Accelerator Concept}

The ram accelerator is a chemical propulsion method for accelerating projectiles to very high speeds ${ }^{6,15}$. In this device, a shaped projectile is accelerated inside a tube filled with a premixed gaseous fuel/oxidizer mixture. In the high-speed modes of the ram accelerator, ignition is 
achieved by means of a detonation wave or other forms of shock-induced combustion. Several methods for generating the detonation wave have been proposed. In the simplest method, a series of shock waves reflected from the tube and the projectile surface increase the temperature of the mixture until the ignition temperature is reached at a designed location. The energy released will then establish a detonation wave or a shock-deflagration wave, depending on the mixture composition, pressure and tube size.
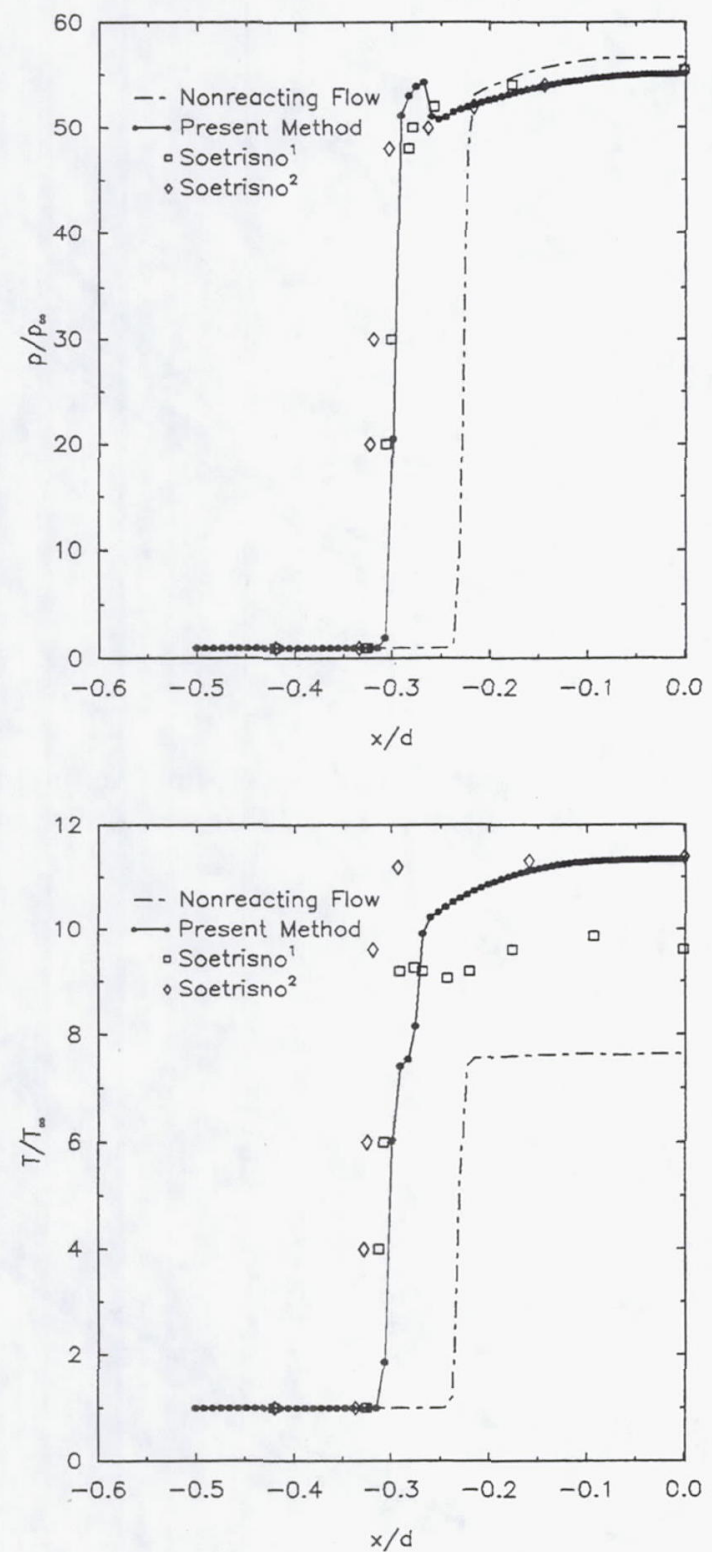

Fig. 8. Pressure and temperature variation along stagnation streamline. Cylinder diameter, $d=7$ $\mathrm{mm}$. Soetrisno ${ }^{1}$ - detailed 13-species, 19-step model; Soetrisno ${ }^{2}$ - quasi-global model.
In a second method, the forward cone angle of the projectile is kept small to reduce drag and prevent premature combustion, and a detonation wave is generated aerodynamically by inserting a sudden, short axisymmetric ramp ${ }^{15}$ with a relatively steep angle, or even a forward facing step as proposed by Rom and Avital ${ }^{16}$ in a similar External Propulsion Accelerator concept. Inviscid simulations of these oblique detonation drive concepts, using simple one step kinetic models, were conducted by Bogdanoff and Brackett ${ }^{17}$ and Tivanov and Rom ${ }^{18}$. Accurate prediction of the ignition delay is important for scaling studies, and viscous effects cannot in general be neglected since the boundary layer can interact with the detonation wave and with other shocks to strongly modify the inviscid picture.

In this paper, we present first a laminar flow investigation of the generation of a detonation wave by means of a double ramp using the newly developed methane oxidation mechanism. Then, we incorporate this concept in a ram accelerator configuration.

Figure 9 shows a schematic of the wave structure for nonreacting and reacting flows. In the nonreacting flow case, the two shock waves $s_{1}$ and $s_{2}$ intersect at point $\mathrm{O}$. From the intersection point $\mathrm{O}$, there is a transmitted shock wave $s_{3}$ and a weaker wave which, at hypersonic speeds, is always an expansion wave. Regions 3 and 4 in Fig $9 \mathrm{a}$ are separated by a slip line $s l_{1}$. The temperature in region 4 is always higher than that of region 3 (except for the boundary layer). This presents the interesting possibility that, for given free-stream conditions, ignition be achieved in region 4 but not in region 3 . This has the advantage that the detonation wave does not interact directly with the body. However, some combustion can still take place along the boundary layer. This situation, in which region 3 acts as a buffer zone between the detonation wave and the body surface, is illustrated in Fig $9 \mathrm{~b}$. Behind the transmitted shock $s_{3}$, there is an induction zone 4 , at the end of which energy release becomes significant and generates a set of deflagration waves through which there is a smooth rise in pressure and temperature. These deflagration waves converge into the shock $s_{3}$, making it steeper until a new oblique detonation wave and a second slip line are formed. An additional compression wave $s_{4}$ is needed to equalize the pressures on the two sides of the slip line $s l_{2}$. The flow structure in zones 4,5 and 6 is similar to that found in a basic detonation on a wedge $^{19}$.

Figures 10 and 11 show temperature contours of a numerical simulation conducted on a double ramp, with $\theta_{1}=18^{\circ}$ and $\theta_{2}=36^{\circ}$. The mixture considered is $\mathrm{CH}_{4}+4 \mathrm{O}_{2}+15.04 \mathrm{~N}_{2}$ (equivalence ratio $\phi=0.5$ ). The free-stream pressure and temperature are $p_{\infty}=1 \mathrm{~atm}$, $T_{\infty}=300^{\circ} \mathrm{K}$, and the Mach number is $M=7.5$. The computations assumed laminar flow and a constant wall 
temperature $T_{w}=600^{\circ} \mathrm{K}$. The length of the flow domain is $40 \mathrm{~cm}$. Besides the flow structure already described, note that combustion occurs in the boundary layer from the corner of the double ramp and downstream. As a result of the reacting boundary layer, a large separation bubble is established at the corner.
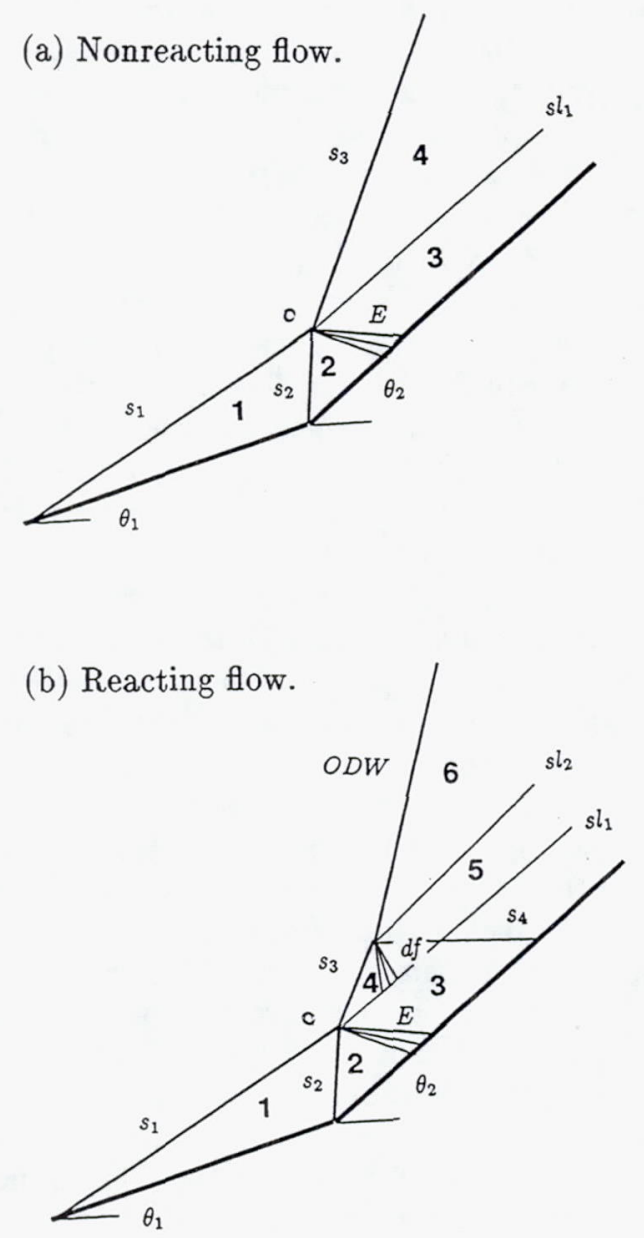

Fig. 9. Schematic of the wave structure on a double ramp for reacting and nonreacting flow. $s$ - shock wave; $s l$ - slip line; $E$ - Prandtl Meyer expansion wave; $d f$ - deflagration waves; $O D W$-oblique detonation wave.

Figure 12 shows the pressure and temperature variation along the gridlines $k=32, k=45$, and $k=65$. For gridline $k=32$, the nonreacting plot shows the pressure and temperature jumps across the two shocks $s_{1}$ and $s_{2}$, followed by the expansion across $E$. The reacting solution along this same gridline shows in addition a jump caused by the separation shock and, behind the expansion, a pressure increase due to combustion. Note that the temperature remains near the nonreacting level ex- cept when this gridline crosses the boundary layer and a temperature rise is observed. Along the $k=45$ gridline the pressure and temperature show the jump across $s_{3}$ followed by a short smooth rise due to the deflagration waves and a final jump caused by the detonation wave. Note that the temperature decreases as the gridline crosses the slip line $s l_{1}$. In the nonreacting flow case, the temperature in region 4 (Fig 9a) is $T_{4} \approx 1800^{\circ} \mathrm{K}$, high enough to ignite the mixture, while the temperature in region 3 is only $T_{3} \approx 1100^{\circ} \mathrm{K}$, too low for ignition.

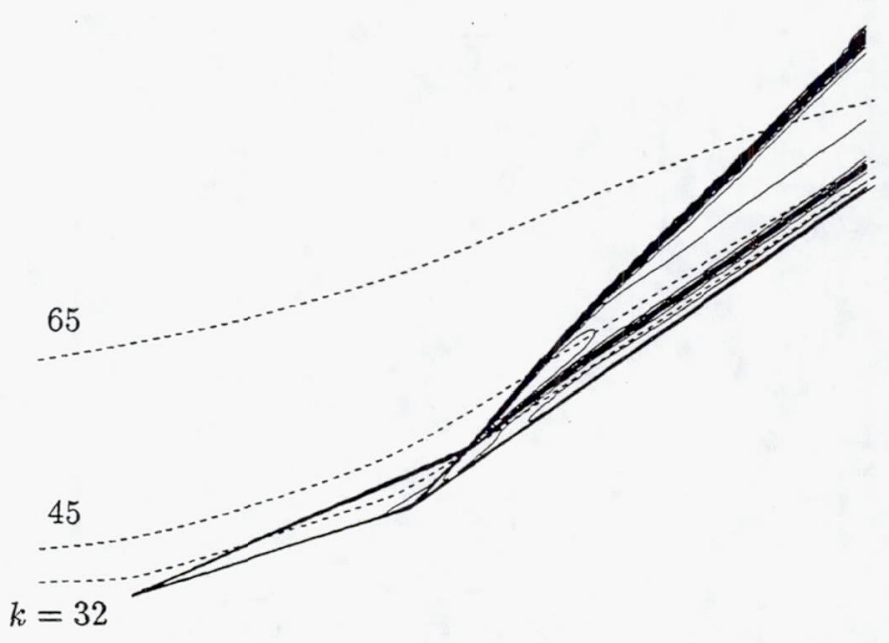

Fig. 10. Temperature contours for nonreacting, $M=7.5$ flow past a double ramp. $\theta_{1}=18^{\circ}, \theta_{2}=36^{\circ}$.

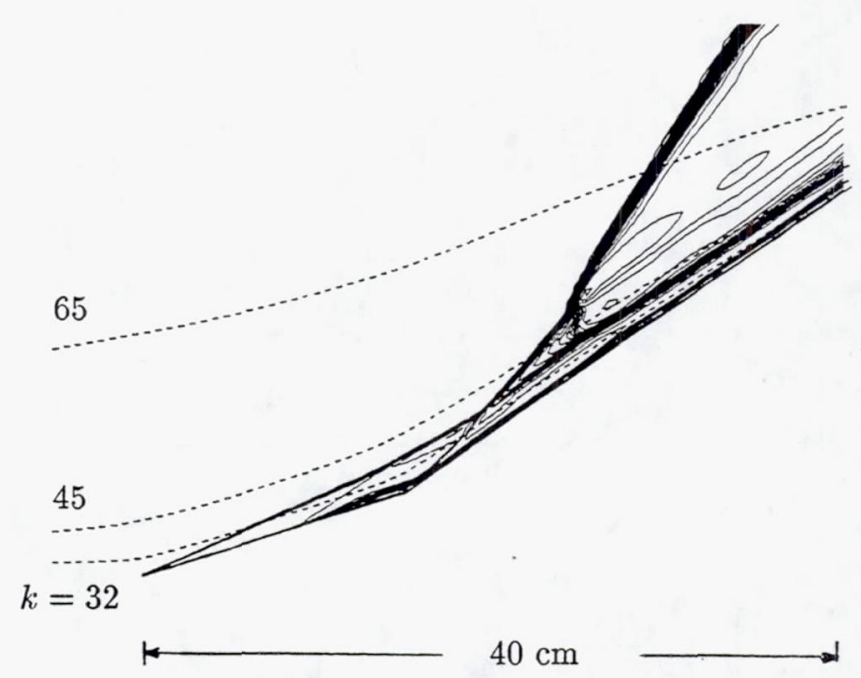

Fig. 11. Temperature contours for reacting, $M=7.5$ flow past a double ramp. $\theta_{1}=18^{\circ}, \theta_{2}=36^{\circ}$. 

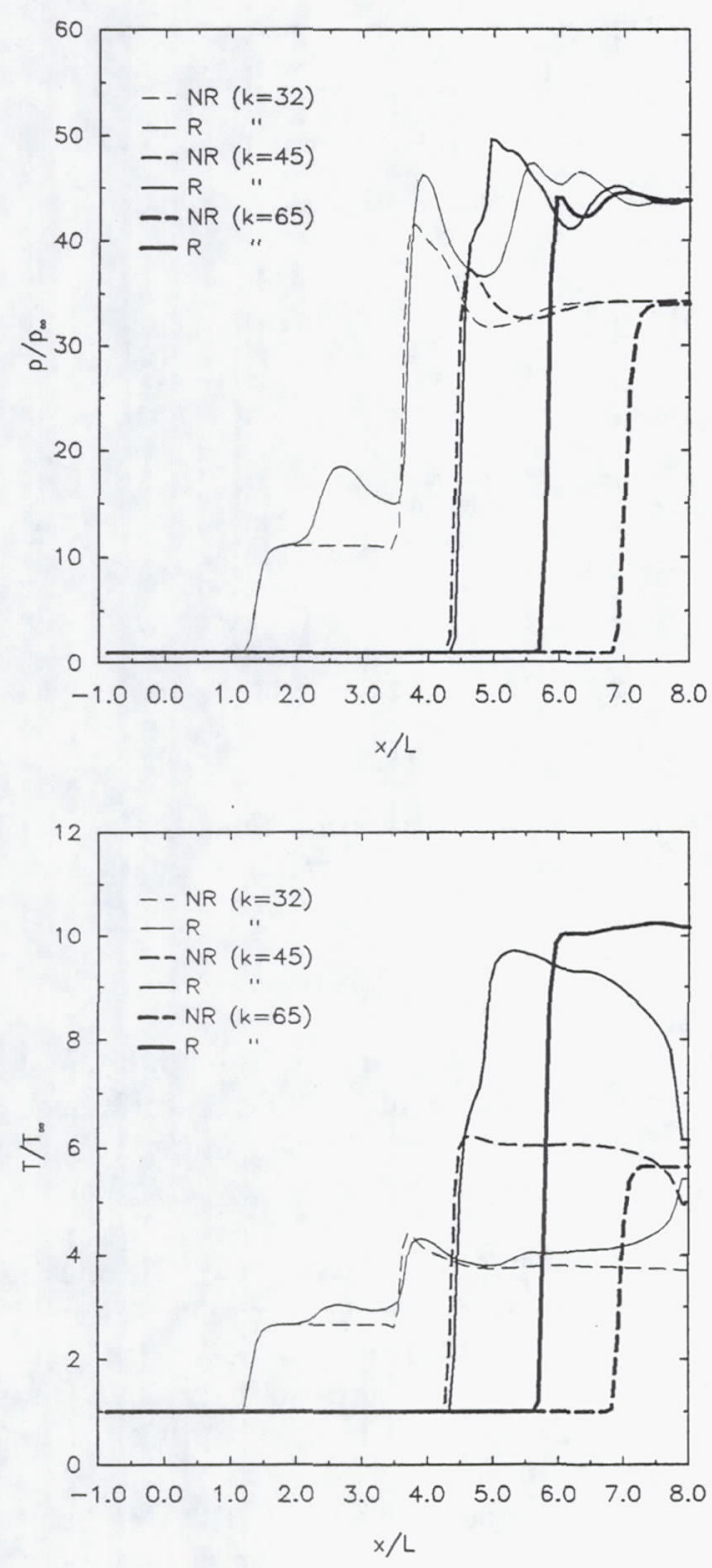

Fig. 12. Pressure and temperature distribution along three $\xi=$ const gridlines (indicated in Fig. 10). NRnonreacting flow; R- reacting flow. Reference length $L=$ $5 \mathrm{~cm}$.

The plot for gridline $k=65$ shows the jump across the oblique detonation wave. Note that the pressure at the outflow boundary is basically uniform (as it should be) but that there are large variations in the temperature profile.

The final set of calculations is conducted on an axisymmetric ram accelerator configuration. The geome- try is based on a $90 \mathrm{~mm}$ tube diameter similar to the ISL ram accelerator, and is shown in Fig. 13. The projectile considered has a $15^{\circ}$ nose cone half angle and a $30^{\circ}$ axisymmetric ramp. The overall length of the projectile is $18.95 \mathrm{~cm}$. Although previous inviscid analyses have placed the ramp downstream of the projectile shoulder ${ }^{15,17}$, viscous calculations indicated very strong shock/boundary layer interactions that strongly modified the ideal inviscid flowfield. The projectile configuration considered in the present work is similar to that proposed in Refs. 16 and 18.

Computations were conducted on a $195 \times 70$ grid for both inviscid and laminar flow. Figures 14 (inviscid) and 15 (laminar) show temperature contours (top half) and $\mathrm{CO}_{2}$ mass fraction contours (bottom half) for a $\mathrm{CH}_{4}+4 \mathrm{O}_{2}+15.04 \mathrm{~N}_{2}$ mixture at $p_{\infty}=1 \mathrm{~atm}, T_{\infty}=$ $300^{\circ} \mathrm{K}$, and a Mach number of $M=9$. Under this conditions, combustion was initiated by the reflected shock from the tube wall. Steeper cone angles or a scale up of the ram accelerator is required in order for the transmitted shock to ignite the mixture in this case. The adiabatic laminar result (Fig. 15) shows combustion along the boundary layer, and a large separation region behind the projectile shoulder caused by the interaction between the reflected detonation and the reacting boundary layer. Note also that the separated boundary layer affects the manner in which the expansion waves emanating from the projectile shoulder interact with the transmitted shock and with the reflected detonation. The pressure distribution along the projectile surface and tube wall is shown in Fig. 16. The high pressure on the back of the projectile caused by the combustion process can be clearly identified. In the laminar calculation, a small pressure rise occurs immediately behind the projectile shoulder due to the separated boundary layer.

\section{Conclusions}

A new reaction mechanism for methane-air combustion was presented. Although this model is still quite complex and requires significant computational power, it can be accurately applied over a wide range of flow parameters. Its use in practical hypersonic flow computations was demonstrated. For specific situations in which some species and/or reactions are presumed to be unimportant, the present model could serve as a benchmark against which simpler models could be compared. 


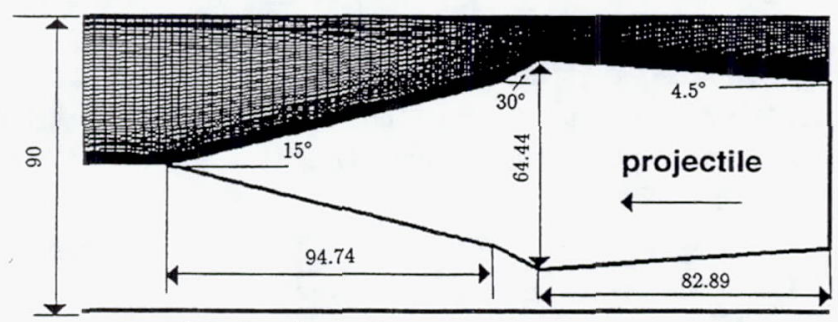

accelerator barrel

Fig. 13. Schematic of ram accelerator. Grid $195 \times 70$. Dimensions are in $\mathrm{mm}$.

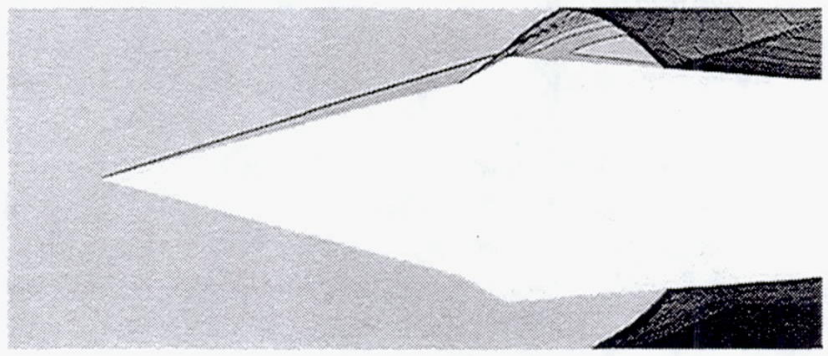

Fig. 14. Temperature contours (top half) and $\mathrm{CO}_{2}$ mass fraction contours (bottom half). Inviscid $M=9$ flow.

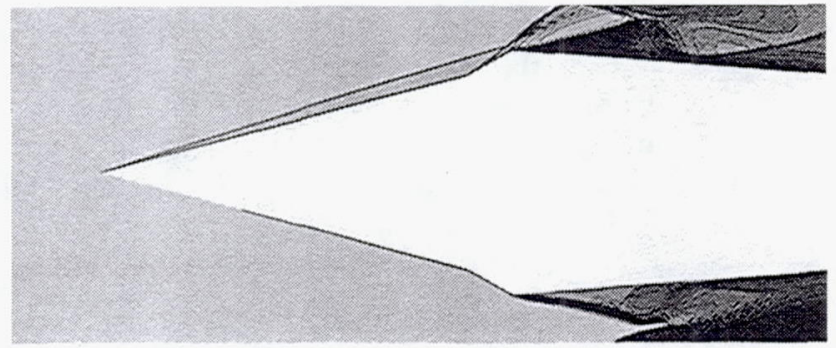

Fig. 15. Temperature contours (top half) and $\mathrm{CO}_{2}$ mass fraction contours (bottom half). Laminar $M=9$ flow.

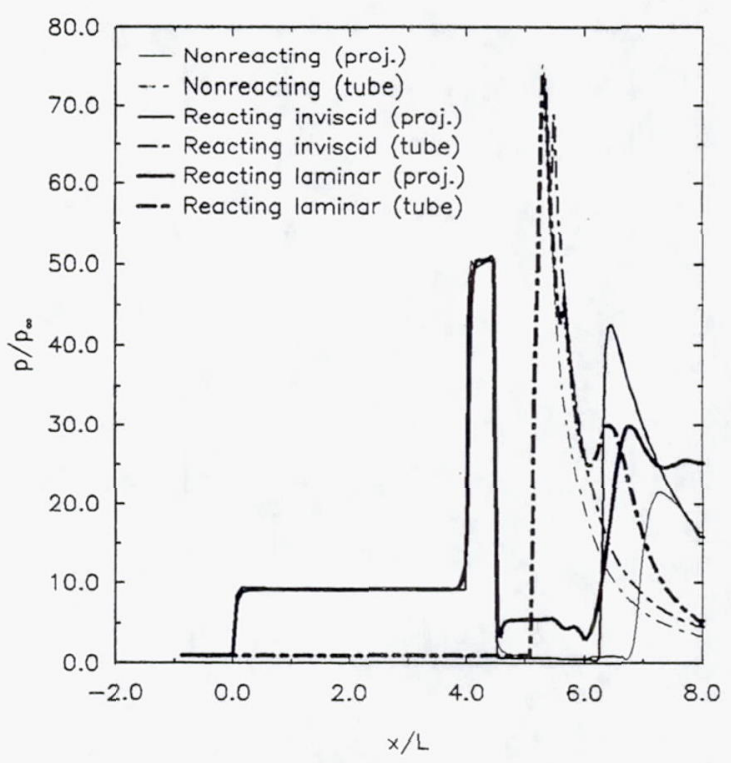

Fig. 16. Pressure distribution along the projectile surface and tube wall; $M=9$. Reference length $L=2.3684$ $\mathrm{cm}$.

\section{References}

[1] Frenklach, M., Wang, H. and Rabinowitz, M.J., "Optimization and Analysis of Large Chemical Kinetic Mechanisms Using the Solution Mapping Method- Combustion of Methane," Prog. Energy Combust. Sci., Vol. 18, 1992, pp. 47-73.

[2] Westbrook, C.K. and Dryer, F.L., "Chemical Kinetic Modeling of Hydrocarbon Combustion," Prog. Energy Combust. Sci., Vol 10, 1984, pp. 1-57.

[3] Warnatz, J., "Rate Coefficients in the C/H/O system," Combustion Chemistry, Chap. 5, Springer, New York, 1984.

[4] Miller, J.A. and Bowman, C.T., "Mechanism and Modeling of Nitrogen Chemistry in Combustion," Prog. Energy Combust. Sci., Vol. 15, 1989, pp. 287-338.

[5] Sloane, T. M., "Ignition and Flame Propagation Modeling With an Improved Methane Oxidation Mechanism," Combustion Sci. Technology, Vol. 63, 1989, pp. 287-313. [6] Hertzberg, A., Bruckner, A.P. and Knowlen, C., "Experimental Investigation of Ram Accelerator Propulsion Modes," Shock Wave International Journal, Vol. 1, No. $1,1991$.

[7] Nuzca, M., "Numerical Simulation of Reacting Flow in a Thermally Choked Ram Accelerator Projectile Launch System," AIAA Paper 91-2490, 1991.

[8] Soetrisno, M., Imlay, S.T. and Roberts, D.W., "Numerical Simulations of the Transdetonative Ram Accelerator Combusting Flow Field on a Parallel Computer," AIAA Paper 92-3249, July 1992. 
[9] Westbrook, C.K. and Dryer, F.L., "Simplified Reaction Mechanisms for the Oxidation of Hydrocarbon Fuels in Flames," Combustion Sci. and Tech., Vol. 27, 1981, pp. 31-43.

[10] Srulijes, J., Smeets, G. and Seiler, F., "Expansion Tube Experiments for the Investigation of RamAccelerator-Related Combustion and Gasdynamic Problems," AIAA Paper 92-3246, July 1992.

[11] Yungster, S., "Numerical Study of ShockWave/Boundary Layer Interactions in Premixed Combustible Gases," AIAA Journal, Vol. 30, No. 10, 1992, pp. 2379-2387.

[12] Wang, H. and Frenklach, M., "Detailed Reduction of Reaction Mechanisms for Flame Modeling," Combustion and Flame, Vol. 87, 1991, pp. 365-370.

[13] Shuen, J.S. and Yoon, S., "Numerical Study of Chemically Reacting Flows Using a Lower-Upper Symmetric Successive Overrelaxation Scheme," AIAA Journal, Vol. 27, No. 12, 1989, pp. 1752-1760.

[14] Yee, H.C., Klopfer, G.H. and Montagnè, J.-L., "HighResolution Shock-Capturing Schemes for Inviscid and Viscous Hypersonic Flows," NASA TM-100097, Apr. 1988.

[15] Hertzberg, A., Bruckner, A.P. and Bogdanoff, D.W., "Ram Accelerator: A New Chemical Method for Accelerating Projectiles to Ultrahigh Velocities," AIAA Journal, vol. 26, No. 2, 1988, pp. 195-203.

[16] Rom, J. and Avital, G.,"The External Propulsion Accelerator: Scramjet Thrust Without Interaction with Accelerator Barrel," AIAA Paper 92-3717, 1992.

[17] Brackett, D.C. and Bogdanoff, D.W., "Computational Investigation of Oblique Detonation Ramjet-inTube Concepts," Journal of Propulsion and Power, vol. 5, No. 3, 1989, pp. 276-281.

[18] Tivanov, G. and Rom, J., "Investigation of Hypersonic Flow of a Detonable Gas Mixture Ahead of a Forward Facing Step," AIAA Paper 93-0611, 1993.

[19] Li, C., Kailasanath, K. and Oran, E.S., "Effects of Boundary Layers on Oblique-Detonation Structures," AIAA Paper 93-0450, 1993. 


\section{Appendix}

Table 2: Methane-air reaction mechanism ${ }^{\dagger}$

\begin{tabular}{|c|c|c|c|c|}
\hline & Reaction & $\mathrm{A}$ & $\Theta$ & $b$ \\
\hline 1 & $\mathrm{H}+\mathrm{O}_{2} \rightleftharpoons \mathrm{OH}+\mathrm{O}$ & $1.59 \times 10^{17}$ & 8491.28 & -0.927 \\
\hline 2 & $\mathrm{O}+\mathrm{H}_{2} \rightleftharpoons \mathrm{OH}+\mathrm{H}$ & $3.87 \times 10^{4}$ & 3151.16 & 2.70 \\
\hline 3 & $\mathrm{OH}+\mathrm{H}_{2} \rightleftharpoons \mathrm{H}_{2} \mathrm{O}+\mathrm{H}$ & $2.16 \times 10^{8}$ & 1725.92 & 1.51 \\
\hline 4 & $\mathrm{OH}+\mathrm{OH} \rightleftharpoons \mathrm{O}+\mathrm{H}_{2} \mathrm{O}$ & $2.10 \times 10^{8}$ & -199.65 & 1.40 \\
\hline 5 & $H+H+M \rightleftharpoons H_{2}+M$ & $6.40 \times 10^{17}$ & 0.0 & -1.0 \\
\hline 6 & $\mathrm{H}+\mathrm{OH}+\mathrm{M} \rightleftharpoons \mathrm{H}_{2} \mathrm{O}+\mathrm{M}$ & $8.40 \times 10^{21}$ & 0.0 & -2.0 \\
\hline 7 & $\mathrm{H}+\mathrm{O}_{2}+\mathrm{M} \rightleftharpoons \mathrm{HO}_{2}+\mathrm{M}$ & $7.00 \times 10^{17}$ & 0.0 & -0.8 \\
\hline 8 & $\mathrm{HO}_{2}+\mathrm{H} \rightleftharpoons \mathrm{OH}+\mathrm{OH}$ & $1.50 \times 10^{14}$ & 505.15 & 0.0 \\
\hline 9 & $\mathrm{HO}_{2}+\mathrm{H} \rightleftharpoons \mathrm{H}_{2}+\mathrm{O}_{2}$ & $2.50 \times 10^{13}$ & 348.79 & 0.0 \\
\hline 10 & $\mathrm{HO}_{2}+\mathrm{O} \rightleftharpoons \mathrm{O}_{2}+\mathrm{OH}$ & $2.00 \times 10^{13}$ & 0.0 & 0.0 \\
\hline 11 & $\mathrm{HO}_{2}+\mathrm{OH} \rightleftharpoons \mathrm{H}_{2} \mathrm{O}+\mathrm{O}_{2}$ & $6.02 \times 10^{13}$ & 0.0 & 0.0 \\
\hline 12 & $\mathrm{H}_{2} \mathrm{O}_{2}+\mathrm{M} \rightleftharpoons \mathrm{OH}+\mathrm{OH}+\mathrm{M}$ & $1.00 \times 10^{17}$ & 22851.89 & 0.0 \\
\hline 13 & $\mathrm{CO}+\mathrm{OH} \rightleftharpoons \mathrm{CO}_{2}+\mathrm{H}$ & $1.22 \times 10^{7}$ & -317.52 & 1.35 \\
\hline 14 & $\mathrm{CO}+\mathrm{O}+\mathrm{M} \rightleftharpoons \mathrm{CO}_{2}+M$ & $3.01 \times 10^{14}$ & 1515.44 & 0.0 \\
\hline 15 & $\mathrm{CHO}+\mathrm{H} \rightleftharpoons \mathrm{CO}+\mathrm{H}_{2}$ & $7.23 \times 10^{13}$ & 0.0 & 0.0 \\
\hline 16 & $\mathrm{CHO}+\mathrm{O} \rightleftharpoons \mathrm{CO}+\mathrm{OH}$ & $3.00 \times 10^{13}$ & 0.0 & 0.0 \\
\hline 17 & $\mathrm{CHO}+\mathrm{OH} \rightleftharpoons \mathrm{CO}+\mathrm{H}_{2} \mathrm{O}$ & $1.00 \times 10^{14}$ & 0.0 & 0.0 \\
\hline 18 & $\mathrm{CHO}+\mathrm{O}_{2} \rightleftharpoons \mathrm{CO}+\mathrm{HO}_{2}$ & $4.20 \times 10^{12}$ & 0.0 & 0.0 \\
\hline 19 & $\mathrm{CHO}+\mathrm{M} \rightleftharpoons \mathrm{CO}+\mathrm{H}+\mathrm{M}$ & $1.86 \times 10^{17}$ & 8551.42 & -1.0 \\
\hline 20 & $\mathrm{CH}_{2} \mathrm{O}+\mathrm{H} \rightleftharpoons \mathrm{CHO}+\mathrm{H}_{2}$ & $1.26 \times 10^{8}$ & 1094.49 & 1.62 \\
\hline 21 & $\mathrm{CH}_{2} \mathrm{O}+\mathrm{O} \rightleftharpoons \mathrm{CHO}+\mathrm{OH}$ & $3.50 \times 10^{13}$ & 1768.01 & 0.0 \\
\hline 22 & $\mathrm{CH}_{2} \mathrm{O}+\mathrm{OH} \rightleftharpoons \mathrm{CHO}+\mathrm{H}_{2} \mathrm{O}$ & $7.23 \times 10^{5}$ & -488.31 & 2.46 \\
\hline 23 & $\mathrm{CH}_{2} \mathrm{O}+\mathrm{O}_{2} \rightleftharpoons \mathrm{CHO}+\mathrm{HO}_{2}$ & $1.00 \times 10^{14}$ & 20085.61 & 0.0 \\
\hline 24 & $\mathrm{CH}_{2} \mathrm{O}+\mathrm{CH} 3 \rightleftharpoons \mathrm{CHO}+\mathrm{CH}_{4}$ & $8.91 \times 10^{-13}$ & -481.09 & 7.4 \\
\hline 25 & $\mathrm{CH}_{2} \mathrm{O}+\mathrm{M} \rightleftharpoons \mathrm{CHO}+\mathrm{H}+\mathrm{M}$ & $5.00 \times 10^{16}$ & 38487.40 & 0.0 \\
\hline 26 & $\mathrm{CH}_{3}+\mathrm{O} \rightleftharpoons \mathrm{CH}_{2} \mathrm{O}+\mathrm{H}$ & $8.43 \times 10^{13}$ & 0.0 & 0.0 \\
\hline 27 & $\mathrm{CH}_{3}+\mathrm{OH} \rightleftharpoons \mathrm{CH}_{2} \mathrm{O}+\mathrm{H}_{2}$ & $8.00 \times 10^{12}$ & 0.0 & 0.0 \\
\hline 28 & $\mathrm{CH}_{3}+\mathrm{O}_{2} \rightleftharpoons \mathrm{CH}_{3} \mathrm{O}+\mathrm{O}$ & $4.30 \times 10^{13}$ & 15503.20 & 0.0 \\
\hline 29 & $\mathrm{CH}_{3}+\mathrm{O}_{2} \rightleftharpoons \mathrm{CH}_{2} \mathrm{O}+\mathrm{OH}$ & $5.20 \times 10^{13}$ & 17559.87 & 0.0 \\
\hline 30 & $\mathrm{CH}_{3}+\mathrm{HO}_{2} \rightleftharpoons \mathrm{CH}_{3} \mathrm{O}+\mathrm{OH}$ & $2.28 \times 10^{13}$ & 0.0 & 0.0 \\
\hline 31 & $\mathrm{CH}_{3}+\mathrm{CHO} \rightleftharpoons \mathrm{CH}_{4}+\mathrm{CO}$ & $3.20 \times 10^{11}$ & 0.0 & 0.5 \\
\hline 32 & $\mathrm{CH}_{3}+\mathrm{CH}_{3} \rightleftharpoons \mathrm{C}_{2} \mathrm{H}_{5}+\mathrm{H}$ & $4.90 \times 10^{12}$ & 5905.41 & 0.0 \\
\hline 33 & $\begin{array}{c}\mathrm{CH}_{4}(+M) \rightleftharpoons \mathrm{CH}_{3}+\mathrm{H}(+M) \\
K_{f}^{0} \\
K_{f}^{\infty} \\
a, b, c \\
\end{array}$ & $\begin{array}{c}1.19 \times 10^{35} \\
7.05 \times 10^{16} \\
0.555\end{array}$ & $\begin{array}{c}53829.68 \\
52788.95 \\
405.62 \\
\end{array}$ & $\begin{array}{c}-4.911 \\
-0.558 \\
4580.87\end{array}$ \\
\hline 34 & $\mathrm{CH}_{4}+\mathrm{H} \rightleftharpoons \mathrm{CH}_{3}+\mathrm{H}_{2}$ & $7.80 \times 10^{6}$ & 3896.85 & 2.11 \\
\hline 35 & $\mathrm{CH}_{4}+\mathrm{O} \rightleftharpoons \mathrm{CH}_{3}+\mathrm{OH}$ & $1.90 \times 10^{9}$ & 4365.91 & 1.44 \\
\hline 36 & $\mathrm{CH}_{4}+\mathrm{O}_{2} \rightleftharpoons \mathrm{CH}_{3}+\mathrm{HO}_{2}$ & $5.60 \times 10^{12}$ & 28179.99 & 0.0 \\
\hline
\end{tabular}


Table 2: continued

\begin{tabular}{|c|c|c|c|c|}
\hline & Reaction & $\bar{A}$ & $\Theta$ & $\bar{b}$ \\
\hline 37 & $\mathrm{CH}_{4}+\mathrm{OH} \rightleftharpoons \mathrm{CH}_{3}+\mathrm{H}_{2} \mathrm{O}$ & $1.50 \times 10^{6}$ & 1226.79 & 2.13 \\
\hline 38 & $\mathrm{CH}_{4}+\mathrm{HO}_{2} \rightleftharpoons \mathrm{CH}_{3}+\mathrm{H}_{2} \mathrm{O}_{2}$ & $4.60 \times 10^{12}$ & 9056.57 & 0.0 \\
\hline 39 & $\mathrm{CH}_{3} \mathrm{O}+\mathrm{H} \rightleftharpoons \mathrm{CH}_{2} \mathrm{O}+\mathrm{H}_{2}$ & $2.00 \times 10^{13}$ & 0.0 & 0.0 \\
\hline 40 & $\mathrm{CH}_{3} \mathrm{O}+\mathrm{OH} \rightleftharpoons \mathrm{CH}_{2} \mathrm{O}+\mathrm{H}_{2} \mathrm{O}$ & $5.00 \times 10^{12}$ & 0.0 & 0.0 \\
\hline 41 & $\mathrm{CH}_{3} \mathrm{O}+\mathrm{O}_{2} \rightleftharpoons \mathrm{CH}_{2} \mathrm{O}+\mathrm{HO}_{2}$ & $4.28 \times 10^{-13}$ & -1775.23 & 7.60 \\
\hline 42 & $\mathrm{CH}_{3} \mathrm{O}+\mathrm{M} \rightleftharpoons \mathrm{CH}_{2} \mathrm{O}+\mathrm{H}+\mathrm{M}$ & $1.00 \times 10^{14}$ & 12628.68 & 0.0 \\
\hline 43 & $\mathrm{C}_{2} \mathrm{H}_{3}+\mathrm{O}_{2} \rightleftharpoons \mathrm{CH}_{2} \mathrm{O}+\mathrm{CHO}$ & $3.98 \times 10^{12}$ & -120.27 & 0.0 \\
\hline 44 & $\mathrm{C}_{2} \mathrm{H}_{4}+\mathrm{H} \rightleftharpoons \mathrm{C}_{2} \mathrm{H}_{3}+\mathrm{H}_{2}$ & $3.16 \times 10^{11}$ & 4029.15 & 0.70 \\
\hline 45 & $\mathrm{C}_{2} \mathrm{H}_{4}+\mathrm{OH} \rightleftharpoons \mathrm{C}_{2} \mathrm{H}_{3}+\mathrm{H}_{2} \mathrm{O}$ & $3.00 \times 10^{13}$ & 1503.41 & 0.0 \\
\hline 46 & $\mathrm{C}_{2} \mathrm{H}_{5}+\mathrm{H} \rightleftharpoons \mathrm{C}_{2} \mathrm{H}_{4}+\mathrm{H}_{2}$ & $3.00 \times 10^{13}$ & 0.0 & 0.0 \\
\hline 47 & $\mathrm{C}_{2} \mathrm{H}_{5}+\mathrm{O}_{2} \rightleftharpoons \mathrm{C}_{2} \mathrm{H}_{4}+\mathrm{HO}_{2}$ & $2.00 \times 10^{12}$ & 2513.71 & 0.0 \\
\hline 48 & $\begin{array}{c}C_{2} H_{5}(+M) \rightleftharpoons C_{2} H_{4}+H(+M) \\
K_{f}^{0} \\
K_{f}^{\infty} \\
a, b, c\end{array}$ & $\begin{array}{c}6.24 \times 10^{39} \\
4.97 \times 10^{10} \\
0.667\end{array}$ & $\begin{array}{c}21384.56 \\
18549.48 \\
653.88\end{array}$ & $\begin{array}{c}-6.80 \\
0.73 \\
8733.74\end{array}$ \\
\hline 49 & $\begin{array}{c}\mathrm{C}_{2} \mathrm{H}_{6}(+M) \rightleftharpoons \\
\mathrm{CH}_{3}+\mathrm{CH}_{3}(+M) \\
K_{f}^{0} \\
K_{f}^{\infty} \\
a, b, c \\
\end{array}$ & $\begin{aligned} & 2.23 \times 10^{61} \\
& 7.10 \times 10^{25} \\
& 0.805\end{aligned}$ & $\begin{array}{c}49895.06 \\
46866.83 \\
302.71 \\
\end{array}$ & $\begin{array}{c}-11.992 \\
-2.792 \\
10730.56 \\
\end{array}$ \\
\hline 50 & $\mathrm{C}_{2} \mathrm{H}_{6}+\mathrm{H} \rightleftharpoons \mathrm{C}_{2} \mathrm{H}_{5}+\mathrm{H}_{2}$ & $5.40 \times 10^{2}$ & 2621.95 & 3.50 \\
\hline 51 & $\mathrm{C}_{2} \mathrm{H}_{6}+\mathrm{OH} \rightleftharpoons \mathrm{C}_{2} \mathrm{H}_{5}+\mathrm{H}_{2} \mathrm{O}$ & $2.20 \times 10^{7}$ & 565.28 & 1.90 \\
\hline 52 & $\mathrm{C}_{2} \mathrm{H}_{6}+\mathrm{CH}_{3} \rightleftharpoons \mathrm{C}_{2} \mathrm{H}_{5}+\mathrm{CH}_{4}$ & $5.50 \times 10^{-1}$ & 4173.48 & 4.00 \\
\hline
\end{tabular}

†Units are in moles, seconds, centimeters, and Kelvins

Third-body efficiencies

(6) $\mathrm{H}_{2}=1.9, \mathrm{O}_{2}=2.6, \mathrm{~N}_{2}=2.6, \mathrm{H}_{2} \mathrm{O}=9.5, \mathrm{CO}=2.6, \mathrm{CO}_{2}=2.6$

(12) $\mathrm{H}_{2}=2.9, \mathrm{O}_{2}=1.2, \mathrm{~N}_{2}=1.2, \mathrm{H}_{2} \mathrm{O}=18.5, \mathrm{CO}=2.1, \mathrm{CO}_{2}=4.3$

(14) $\mathrm{O}_{2}=12.0, \mathrm{~N}_{2}=2.0, \mathrm{CO}=3.0, \mathrm{CO}_{2}=7.0$

(19) $\mathrm{H}_{2}=1.87, \mathrm{H}_{2} \mathrm{O}=8.12$

(25) $\mathrm{H}_{2}=2.9, \mathrm{O}_{2}=1.2, \mathrm{~N}_{2}=1.2, \mathrm{H}_{2} \mathrm{O}=18.5, \mathrm{CO}=2.1, \mathrm{CO}_{2}=4.3$

(42) $\mathrm{H}_{2}=2.9, \mathrm{O}_{2}=1.2, \mathrm{~N}_{2}=1.2, \mathrm{H}_{2} \mathrm{O}=18.5, \mathrm{CO}=2.1, \mathrm{CO}_{2}=4.3$ 
Public reporting burden for this collection of information is estimated to average 1 hour per response, including the time for reviewing instructions, searching existing data sources, gathering and maintaining the data needed, and completing and reviewing the collection of information. Send comments regarding this burden estimate or any other aspect of this Meadquarters Services, Directorate for Information Operatic Davis Highway, Suite 1204, Arlington, VA 22202-4302, and to the Office of Management and Budget, Paperwork Reduction Project (0704-0188), Washington, DC 20503.

\begin{tabular}{|l|l|r|} 
1. AGENCY USE ONLY (Leave blank) & $\begin{array}{c}\text { 2. REPORT DATE } \\
\text { June } 1993\end{array}$ & $\begin{array}{r}\text { 3. REPORT TYPE AND DATES COVERED } \\
\text { Technical Memorandum }\end{array}$
\end{tabular}

4. TITLE AND SUBTITLE

Numerical Study Shock-Induced Combustion in Methane-Air Mixtures

6. $\operatorname{AUTHOR}(\mathrm{S})$

Shaye Yungster and Martin J. Rabinowitz

7. PERFORMING ORGANIZATION NAME(S) AND ADDRESS(ES)

National Aeronautics and Space Administration

Lewis Research Center

Cleveland, Ohio 44135-3191

9. SPONSORING/MONITORING AGENCY NAME(S) AND ADDRESS(ES)

National Aeronautics and Space Administration

Washington, D.C. 20546-0001
5. FUNDING NUMBERS

WU-505-90-5K

8. PERFORMING ORGANIZATION REPORT NUMBER

$\mathrm{E}-8138$

10. SPONSORING/MONITORING AGENCY REPORT NUMBER

NASA TM-106354

ICOMP-93-32

AIAA-93-1917

11. SUPPLEMENTARY NOTES

Prepared for the 29th Joint Propulsion Conference and Exhibit cosponsored by the AIAA, SAE, ASME, and ASEE, Monterey, California, June 28-30, 1993. Martin J. Rabinowitz, NASA Lewis Research Center and Shaye Yungster, Institute for Computational Mechanics in Propulsion, NASA Lewis Research Center, (work funded under NASA Cooperative Agreement NCC3-233). ICOMP Program Director, Louis A. Povinelli, (216) 433-5818.

12a. DISTRIBUTION/AVAILABILITY STATEMENT 12b. DISTRIBUTION CODE

Unclassified-Unlimited

Subject Category 34

13. ABSTRACT (Maximum 200 words)

The shock-induced combustion of methane-air mixtures in hypersonic flows is investigated using a new reaction mechanism consisting of 19 reacting species and 52 elementary reactions. This reduced model is derived from a full kinetic mechanism via the Detailed Reduction technique. Zero-dimensional computations of several shock-tube experiments are presented first. The reaction mechanism is then combined with a fully implicit Navier-Stokes CFD code to conduct numerical simulations of two-dimensional and axisymmetric shock-induced combustion experiments of stoichiometric methane-air mixtures at a Mach number of $M=6.61$. Applications to the ram accelerator concept are also presented.

Detonation waves; TVD schemes; Ram accelerator; Detailed reduction

\begin{tabular}{|c|c|c|}
\hline $\begin{array}{c}\text { 17. SECURITY CLASSIFICATION } \\
\text { OF REPORT } \\
\text { Unclassified }\end{array}$ & $\begin{array}{c}\text { 18. SECURITY CLASSIFICATION } \\
\text { OF THIS PAGE } \\
\text { Unclassified }\end{array}$ & $\begin{array}{c}\text { 19. SECURITY CLASSIFICATION } \\
\text { OF ABSTRACT } \\
\text { Unclassified }\end{array}$ \\
\hline
\end{tabular}

